\title{
Role of the chemistry of soil organic matter on the sorption of diuron
}

\author{
A. G. Ahangar ${ }^{1,2}$, R. J. Smernik ${ }^{1}$ \& R. S. Kookana ${ }^{1,3}$ \\ ${ }^{I}$ Soil and Land Systems, School of Earth and Environmental Sciences, \\ Adelaide University, Australia \\ ${ }^{2}$ Department of Soil Science, University of Zabol, Zabol, Iran \\ ${ }^{3}$ CSIRO, Land \& Water, Adelaide, Australia
}

\begin{abstract}
The influence of organic matter chemistry on the sorption of diuron to soils collected from a small ( 2 ha) field was investigated. Organic carbon-normalized sorption coefficients $\left(\mathrm{K}_{\mathrm{OC}}\right)$, determined by batch sorption, varied between 405 and $598 \mathrm{Lkg}^{-1}$ amongst 10 A11 horizons, and between 547 and $975 \mathrm{Lkg}^{-1}$ amongst 10 matching $\mathrm{A} 12$ horizons. In all cases $\mathrm{K}_{\mathrm{OC}}$ was greater for the A12 horizon than the corresponding A11 horizon by $27-81 \%$. Organic matter chemistry of the $\mathrm{A} 11$ and $\mathrm{A} 12$ horizons was determined using solid-state ${ }^{13} \mathrm{C}$ nuclear magnetic resonance (NMR) spectroscopy. $\mathrm{K}_{\mathrm{OC}}$ was positively correlated with aryl $C\left(r^{2}=0.61\right.$, significance level 0.001$)$ and negatively correlated with O-alkyl C ( $\mathrm{r}^{2}=0.88$, significance level $\left.<0.001\right)$ as a single factor and as a combination of both we also propose $\mathrm{A}$ index $\left(\mathrm{r}^{2}=0.65\right.$, significance level 0.001). Little change in soil mineralogy across a very small field led to diminished organic matter and clay mineral interactions, allowing the effect of organic matter chemistry on $\mathrm{K}_{\mathrm{OC}}$ to be clearly seen.
\end{abstract}

Keywords: sorption, diuron, NMR spectroscopy.

\section{Introduction}

Diuron, N- (3,4-dichlorophenyl)-N, N-dimethyl-urea, is one of the phenyl amide family and belongs to the subclass of phenyl urea. Diuron is a toxic and slightly hazardous type III pesticide on the basis of the EPA (Environmental Protection Agency, USA) and is considered as a priority hazardous substance (PHS) by the European Commission. 
The toxicity, degradability and mobility of organic pollutants in soils are largely controlled by their sorption to soil particles. For non-ionic species, such as diuron, the main role in the sorption process is played by soil organic matter and is most commonly described as a linear (i.e. concentration-independent) partitioning between the solution and soil organic matter. In this most simple of models, just one parameter, $\mathrm{K}_{\mathrm{OC}}$, the $\mathrm{C}$-normalized partition coefficient, quantifies the sorption interaction and it is also independent of soil properties other than $\mathrm{C}$ content [8]. In this sense $\mathrm{K}_{\mathrm{OC}}$ is analogous to $\mathrm{K}_{\mathrm{OW}}$, the octanolwater partitioning coefficient, and indeed good correlations between $\mathrm{K}_{\mathrm{OC}}$ and $\mathrm{K}_{\mathrm{OW}}$ have been reported $[9,10]$.

In some situations, the simple organic matter partitioning model does not provide an adequate description of the sorption interaction in soils such as: sorption is not independent of concentration, sorption is not fully reversible, sorption kinetics are very slow, or there are significant competition effects between sorbate molecules and situations where either organic matter is not the sole sorbent and soil minerals contribute significantly to sorption or different sources of organic matter have different sorption affinities [28]. It is this last situation that we will focus on here. It is well documented that $\mathrm{K}_{\mathrm{OC}}$ varies widely for organic matter types as different and distinct as plant biopolymers (cellulose, lignin, cuticle), peat, coal and shale [5,6,24]. It has also been shown that different humic fractions from the same soil can have different $\mathrm{K}_{\mathrm{OC}}$ values $[5,6,16,19,23]$ and that modification of organic matter can affect $\mathrm{K}_{\mathrm{OC}}$ of humic substances [25]. However, it is less certain the extent to which differences in the nature of organic matter are responsible for variations in $\mathrm{K}_{\mathrm{OC}}$ between soils. Alternative causes, such as sorption by soil minerals [27] and blocking of sorption sites by minerals [4] have also been proffered. The most simple and obvious way to prove a link between organic matter chemistry and $\mathrm{K}_{\mathrm{OC}}$ would be show a correlation between $\mathrm{K}_{\mathrm{OC}}$ and a parameter that measures some aspect of organic matter chemistry. Such correlations have been shown for model systems $[5,24]$ and humic extracts [19], but their relevance to whole soils is questionable.

In this study, we have restricted our attention to soils collected from a single $\sim 2$ ha site in which many soil variables (e.g. mineralogy, $\mathrm{pH}$, land-use) are reasonably constant. Previous studies have found $\mathrm{K}_{\mathrm{OC}}$ to vary less at these scales than at larger scales [11,21]. Our aim is to test whether under these restricted conditions, a relationship between $\mathrm{K}_{\mathrm{OC}}$ and organic matter chemistry as determined by solid-state ${ }^{13} \mathrm{C}$ NMR spectroscopy can be identified.

\section{Materials and methods}

\subsection{Soil and chemicals}

The sorption studies were carried out on soil from a site at Flaxley Agriculture Centre, Mount Lofty Ranges, South Australia. The soils are a series of Ferric, Eutrophic Red Chromosols on the upper to mid-slopes and Mottled Eutrophic Yellow Chromosols on the lower slope with neutral to slightly acidic $\mathrm{pH}$ [15]. The A1 horizons were subdivided into A11 and A12 horizons based on the darker colour of the former. 
Diuron ( $>99 \%$ purity) was purchased from Sigma-Aldrich (Sydney, Australia). HPLC grade solvents and calcium chloride were obtained from Merck Pty Limited (Victoria, Australia). A stock solution of $1000 \mathrm{mg} / \mathrm{L}$ diuron was prepared in methanol.

\subsection{Sorption experiments}

Sorption experiments were carried out using a batch equilibration technique at 25 ${ }^{\circ} \mathrm{C}$. To minimize changes in ionic strength and to avoid dispersion, $0.01 \mathrm{M} \mathrm{CaCl}_{2}$ was used as a background solution and $200 \mathrm{mgL}^{-1} \mathrm{HgCl}_{2}$ was used as a microbial growth inhibitor. For single point measurements, soil $(1 \mathrm{~g})$ and diuron solution $\left(1.5 \mathrm{mgL}^{-1}, 10 \mathrm{~mL}\right)$ were shaken end-over-end for 24 hours. At the end of the equilibrium period, suspensions were centrifuged at $3000 \mathrm{~g}$ for 20 minutes and 1 $\mathrm{mL}$ aliquots of the supernatant were filtered through $0.45 \mu \mathrm{m}$ Teflon filters and analysed.

Diuron concentrations were determined using an Agilent 1100 series high performance liquid chromatograph (HPLC) equipped with diode array detector and $\mathrm{C} 18$ column $(250 \mathrm{~mm} \times 4.6 \mathrm{~mm}$ internal diameter, $5 \mu \mathrm{m}$ particle size $)$. The mobile phase was $70 \%$ acetonitrile and $30 \%$ water, and the flow rate was $1 \mathrm{~mL}$ per minute. Diuron was detected at a UV wavelength of $210 \mathrm{~nm}$. The retention time for diuron under these conditions was 4.48 minutes. The detection limit was approximately $0.05 \mathrm{mgL}^{-1}$. Blanks without diuron and without soil were analysed and appropriate corrections were applied. Sorbed concentrations were calculated from the difference between the initial solution concentration and equilibrium solution concentration.

\subsection{NMR analysis}

The soils were HF-treated prior to NMR analysis using the procedure of Skjemstad et al. [26]. Solid-state ${ }^{13} \mathrm{C}$ cross polarization (CP) NMR spectra were acquired with magic angle spinning (MAS) at a ${ }^{13} \mathrm{C}$ frequency of $50.3 \mathrm{MHz}$ on a Varian Unity200 spectrometer. Samples were packed in a $7 \mathrm{~mm}$ diameter cylindrical zirconia rotor with Kel-F end-caps and spun at $5000 \pm 100 \mathrm{~Hz}$ in a Doty Scientific MAS probe. A 1-ms contact time and a 1-s recycle delay were used, and 4000 transients were collected for each spectrum. Free induction decays were acquired with a sweep width of $40 \mathrm{kHz} ; 1216$ data points were collected over an acquisition time of $15 \mathrm{~ms}$. All spectra were zero-filled to 8192 data points and processed with a $50 \mathrm{~Hz}$ Lorentzian line broadening and a $0.005 \mathrm{~s}$ Gaussian broadening. Chemical shifts were externally referenced to the methyl resonance of hexamethylbenzene at $17.36 \mathrm{ppm}$.

\section{Results and discussion}

Sorption coefficients $\left(\mathrm{K}_{\mathrm{d}}\right)$ for the 10 upper two horizons soils are presented in Table 1. While Figure 1 shows the variation of $\mathrm{K}_{\mathrm{d}}$ with depth, in all cases $\mathrm{Kd}$ for the A11 horizons were higher than the A12 horizons. Figure 2 shows that $\mathrm{K}_{\mathrm{d}}$ across all samples was strongly correlated with the soil $\mathrm{C}$ content $\left(\mathrm{r}^{2}=0.71\right.$, 
significance level 0.001). The relationship between $\mathrm{K}_{\mathrm{d}}$ for diuron and $\mathrm{C}$ content is consistent with the findings of others $[14,18]$. Sorption coefficients normalized for organic $\mathrm{C}$ content $\left(\mathrm{K}_{\mathrm{OC}}\right)$ were calculated and these are also presented in Table 1. The average $\mathrm{K}_{\mathrm{OC}}$ value across all of the soils was $723 \mathrm{Lkg}^{-1}$, which is higher than the average diuron $\mathrm{K}_{\mathrm{OC}}$ values reported in previous studies [13,14,18,20,22]. However, the average for the A11 horizons of $487 \mathrm{Lkg}^{-1}$ is quite consistent with these literature values and represents a more meaningful comparison given that most literature values are for topsoils.

The variation of $\mathrm{K}_{\mathrm{OC}}$ with depth is most clear in Figure 3, which shows that $\mathrm{K}_{\mathrm{OC}}$ for the A11 horizon was lower than for the A12. Figure 3 confirms that differences in $\mathrm{K}_{\mathrm{OC}}$ between the A11 and A12 horizons are very consistent, with $\mathrm{K}_{\mathrm{OC}}$ on average $46 \%$ higher for the $\mathrm{A} 12$ horizon.

Sorption coefficients were determined at a single initial concentration of sorbate $\left(1.5 \mathrm{mgL}^{-1}\right)$ and in each case the same volume of solution and amount of soil was used. The differences in $\mathrm{K}_{\mathrm{OC}}$ between the soil samples, and in particular the patterns of diuron $\mathrm{K}_{\mathrm{OC}}$ variation may reflect the differences in the nature of soil organic matter with depth as well as its differences horizontally across the

Table 1: $\quad \mathrm{C}$ content and sorption coefficients $\left(\mathrm{K}_{\mathrm{d}}\right.$ and $\left.\mathrm{K}_{\mathrm{OC}}\right)$ for each soil horizon. Standard deviations shown in brackets.

\begin{tabular}{cccccr}
\hline $\begin{array}{c}\text { Core } \\
\text { number }\end{array}$ & Horizon & $\begin{array}{c}\text { Depth } \\
(\mathrm{cm})\end{array}$ & $\begin{array}{c}\text { C content } \\
(\%)\end{array}$ & $\begin{array}{c}\mathrm{K}_{\mathrm{d}} \\
(\mathrm{L} / \mathrm{kg} \text { soil })\end{array}$ & $\begin{array}{c}\mathrm{K}_{\mathrm{OC}} \\
(\mathrm{L} / \mathrm{kg} \text { soil C) }\end{array}$ \\
\hline 6 & A11 & $0-6$ & 4.9 & $24.8(0.3)$ & $507(7)$ \\
6 & A12 & $6-17$ & 1.5 & $13.2(0.2)$ & $884(10)$ \\
10 & A11 & $0-5$ & 4.2 & $25.3(0.3)$ & $598(6)$ \\
10 & A12 & $5-15$ & 2.0 & $18.6(0.9)$ & $918(44)$ \\
17 & A11 & $0-4$ & 5.7 & $31.5(0.3)$ & $556(4)$ \\
17 & A12 & $4-16$ & 2.5 & $19.0(0.9)$ & $762(36)$ \\
22 & A11 & $0-9$ & 4.6 & $21.2(0.4)$ & $459(9)$ \\
22 & A12 & $9-17$ & 1.9 & $10.9(0.1)$ & $583(3)$ \\
28 & A11 & $0-5$ & 3.6 & $16.9(0.1)$ & $473(3)$ \\
28 & A12 & $5-12$ & 1.6 & $10.7(0.6)$ & $679(36)$ \\
30 & A11 & $0-8$ & 3.6 & $17.3(0.6)$ & $477(17)$ \\
30 & A12 & $8-19$ & 1.6 & $10.6(0.5)$ & $678(35)$ \\
33 & A11 & $0-5$ & 4.2 & $17.7(0.3)$ & $428(7)$ \\
33 & A12 & $5-18$ & 2.1 & $14.8(0.5)$ & $707(26)$ \\
35 & A11 & $0-9$ & 3.8 & $17.0(0.1)$ & $452(3)$ \\
35 & A12 & $9-17$ & 1.5 & $8.8(0.3)$ & $579(22)$ \\
40 & A11 & $0-8$ & 3.7 & $15.0(0.1)$ & $405(3)$ \\
40 & A12 & $8-18$ & 1.6 & $8.9(0.5)$ & $547(31)$ \\
44 & A11 & $0-6$ & 5.5 & $29.4(3.0)$ & $538(55)$ \\
44 & A12 & $6-18$ & 2.3 & $22.7(0.6)$ & $975(24)$ \\
\hline & & & & &
\end{tabular}




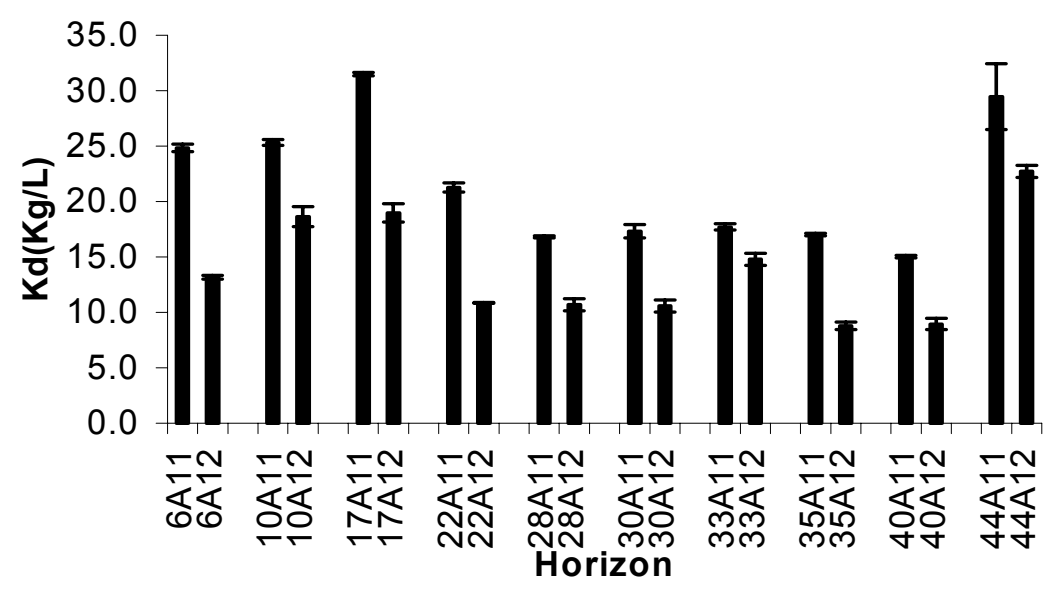

Figure 1: Comparison of $\mathrm{K}_{\mathrm{d}}$ values for corresponding $\mathrm{A} 11$ and $\mathrm{A} 12$ horizons. Error bars show standard deviation Comparison of $\mathrm{K}_{\mathrm{d}}$.

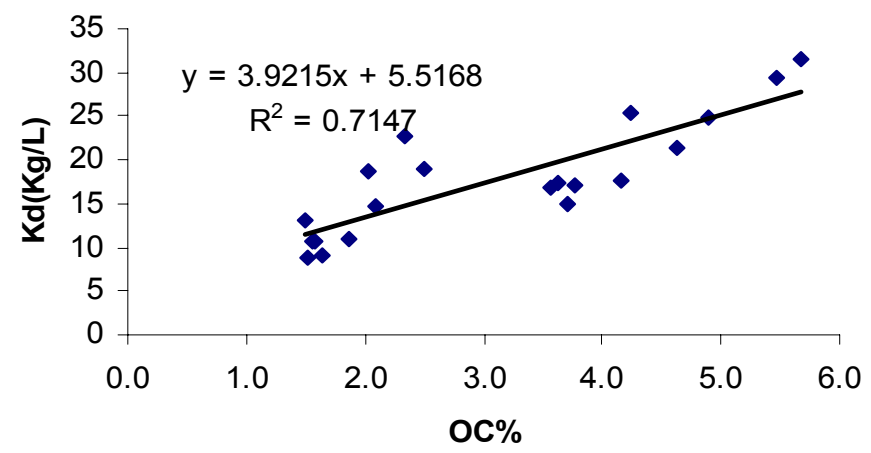

Figure 2: $\quad$ Relationship between organic carbon and $K_{d}$ values for $A 11$ and A12 horizons.

site. These differences can be seen clearly in Figures 3. Preliminary experiments showed sorption isotherm are linear thus it is unlikely that non-linearity of sorption isotherms is the cause of the differences in sorption between soil A11 and A12 horizons.

The solid-state ${ }^{13} \mathrm{C}$ CP NMR spectra of the soils (Figure 4) do indicate that there are differences in the chemistry of the organic matter between the soils. Consistent differences between the A11 and A12 horizons are evident - the aryl $\mathrm{C}$ peak at $\sim 130 \mathrm{ppm}$ is stronger for the A12 horizons and the ratio of the alkyl resonance $(\sim 30 \mathrm{ppm})$ to the O-alkyl resonance $(\sim 75 \mathrm{ppm})$ is greater for the A12 


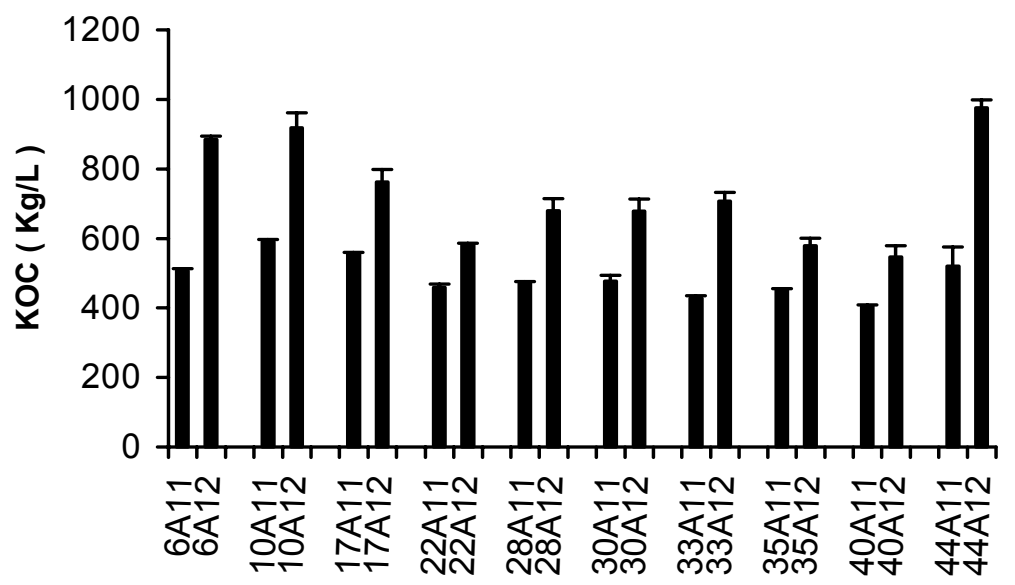

Figure 3: Comparison of $\mathrm{K}_{\mathrm{OC}}$ values for corresponding $\mathrm{A} 11$ and $\mathrm{A} 12$ horizons. Error bars show standard deviation.

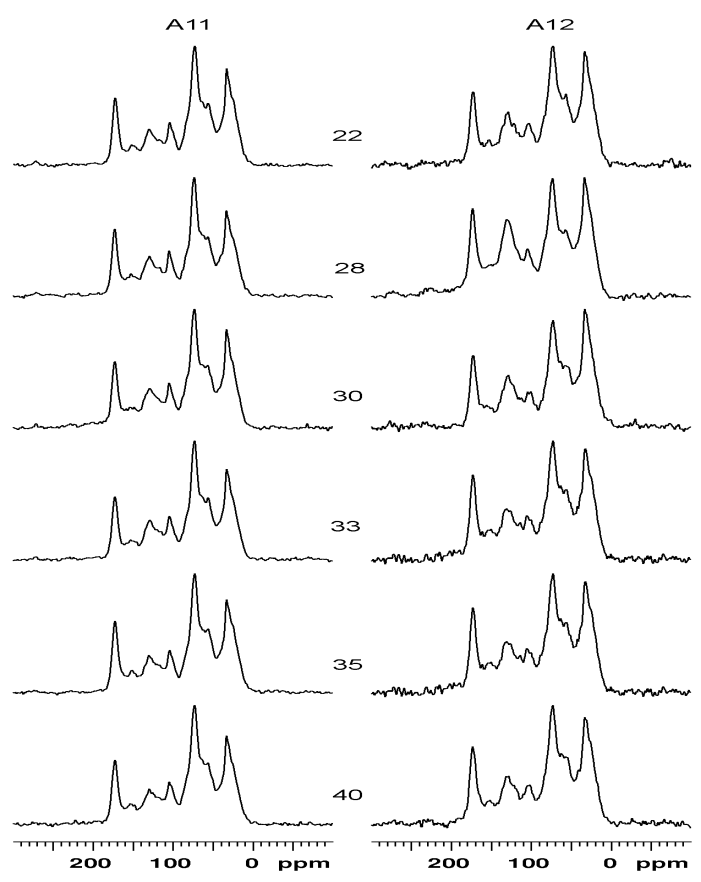

Figure 4: Solid-state ${ }^{13} \mathrm{C}$ NMR spectra of six A11 and six corresponding A12 horizons (Ahangar et al [1]). 
horizons. These differences are consistent with the organic matter in the A12 horizons being more decomposed, and containing less fresh plant residues [3,12].

There are also differences in the ${ }^{13} \mathrm{C}$ CP NMR spectra within the A11 and, especially, the A12 horizons. For example, the aryl resonances in the spectra of samples 28A12 and 30A12 are stronger than in the spectra of the other A12 horizons.

The distribution of $\mathrm{C}$ types was determined from the ${ }^{13} \mathrm{C} \mathrm{CP}$ NMR spectra by integration across four chemical shift regions - 185-165 ppm (carbonyl), 165110 ppm (aryl), 110-45 ppm (O-alkyl) and 45-0 ppm (alkyl). Figure 5 shows that $\mathrm{K}_{\mathrm{OC}}$ is positively correlated with aryl $\mathrm{C}\left(\mathrm{r}^{2}=0.59\right.$, significance level 0.001$)$ and negatively correlated with O-alkyl $\mathrm{C}\left(\mathrm{r}^{2}=0.84\right.$, significance level $\left.<0.001\right)$. Considering the point that the effect of each $\mathrm{C}$ types on sorption properties cannot be taken into account separately in natural environment such as soil, we also propose the A index [(aryl/O-alkyl)*100], in this simplest view of combination, both significant negative and positive effects of different carbon types on soil sorption characteristics are considered together.

These findings confirm that the chemistry as well as the amount of organic matter influences the sorption affinity of these soils. Aromatic $\mathrm{C}$ is identified as having the highest affinity for diuron, a finding consistent with previous similar studies on soils $[2,29]$, and humic substances $[6,7]$.

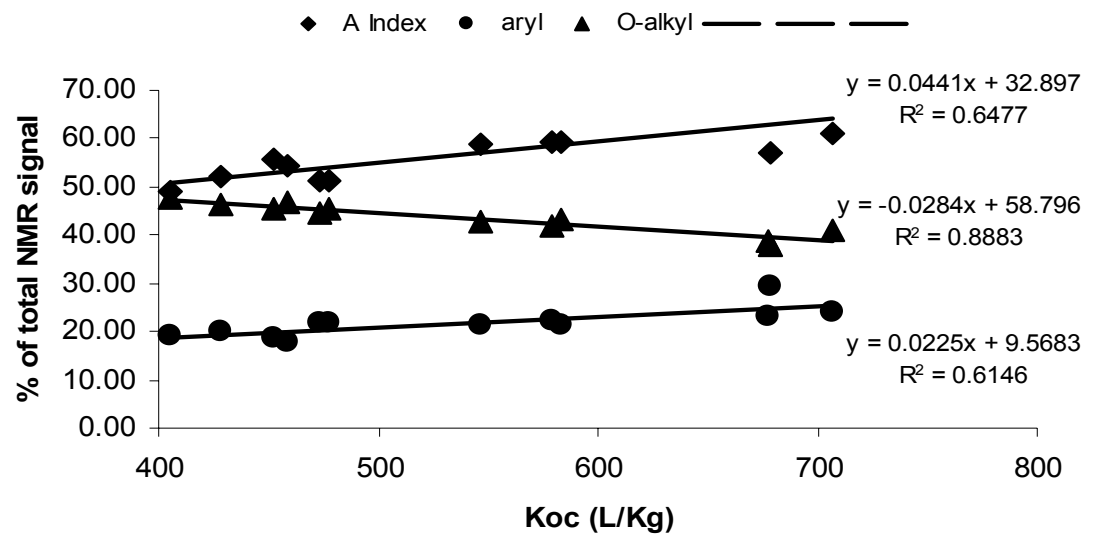

Figure 5: $\quad$ Plot of NMR integral area versus $\mathrm{K}_{\mathrm{OC}}$.

Conversely, the negative correlation between O-alkyl $\mathrm{C}$ and $\mathrm{K}_{\mathrm{OC}}$ identifies this $\mathrm{C}$ type as having the lowest affinity for diuron, a finding consistent with the results of Kile et al [17].

\section{Conclusion}

We conclude that not only the amount of soil organic matter but also the chemistry of soil organic matter can play crucial role on the sorption properties 
of soil. Solid-state ${ }^{13} \mathrm{C}$ nuclear magnetic resonance (NMR) spectroscopy showed that $\mathrm{K}_{\mathrm{OC}}$ was positively correlated with aryl $\mathrm{C}\left(\mathrm{r}^{2}=0.61\right)$, and negatively correlated with $\mathrm{O}$-alkyl $\mathrm{C}\left(\mathrm{r}^{2}=0.88\right)$. There is growing evidence that interactions between organic matter and clay minerals strongly affect $\mathrm{K}_{\mathrm{OC}}$. However, because the soil mineralogy varies little across the field, the influence of these interactions is greatly diminished, allowing the effect of organic matter chemistry on $\mathrm{K}_{\mathrm{OC}}$ to be seen clearly. This study in some way reconciles studies that show strong correlations between $\mathrm{K}_{\mathrm{OC}}$ and the chemistry of purified organic materials and the general lack of such correlations for whole soils.

\section{References}

[1] Ahangar, A.G., Smernik, R.J., Kookana, R.S., Chittleborough, D.J., Clear effects of soil organic matter chemistry, as determined by NMR spectroscopy, on the sorption of diuron. Chemosphere, 70, pp. 1153-1160, 2008.

[2] Ahmad, R., Kookana, R.S., Alston, A., Skjemstad, J.O., The nature of soil organic matter affects sorption of pesticides. 1. Relationships with carbon chemistry as determined by 13C CPMAS NMR spectroscopy. Environ. Sci. Techno, 35, pp. 878-884, 2001.

[3] Baldock, J.A., Oades, J.M., Nelson, P.N., Skene, T.M., Golchin, A., Clarke, P., Assessing the extent of decomposition of natural organic materials using solid-state 13C NMR spectroscopy. Aust. J. Soil Res, 35, pp. 1061-1083, 1997.

[4] Celis, R., de Jonge, H., de Jonge, L.W., Real, M., Hermosin, M.C., Cornejo, J., The role of mineral and organic components in phenanthrene and dibenzofuran sorption by soil. Eur. J. Soil Sci, 57, pp. 308-319, 2006.

[5] Chefetz, B., Deshmukh, A.P., Hatcher, P.G., Pyrene sorption by natural organic matter. Environ. Sci. Technol, 34, pp. 2925-2930, 2000.

[6] Chen, Z., Xing, B., McGill, W.B., Dudas, M.J., alpha-Naphthol sorption as regulated by structure and composition of organic substances in soils and sediments. Can. J. Soil Sci, 76, pp. 513-522, 1996.

[7] Chin, Y.-P., Aiken, G.R., Danielsen, K.M., Binding of pyrene to aquatic and commercial humic substances: the role of molecular weight and aromaticity. Environ. Sci. Technol, 31, pp. 1630-1635, 1997.

[8] Chiou, C.T., Theoretical considerations of the partition uptake of nonionic organic compounds by soil organic matter. Reactions and movement of organic chemicals in soils, ed. Sawhney, B.L., Brown, K, Soil Science Society of America, Inc., Madison, WI, pp. 1-29, 1989.

[9] Chiou, C.T., Peters, L.J., Freed, V.H., A physical concept of soil-water equilibria for nonionic organic compounds. Science, 206, pp. 831-832, 1979.

[10] Chiou, C.T., Porter, P.E., Schmeddling, D.W., Partition equilibria of nonionic organic compounds between soil organic matter and water. Environ. Sci. Technol, 17, pp. 227-231, 1983. 
[11] Coquet, Y., Barriuso, E., Spatial variability of pesticide adsorption within the topsoil of a small agricultural catchment. Agronomie, 22, pp.389-398, 2002.

[12] Dalmolin, R.S.D., Goncalves, C.N., Dick, D.P., Knicker, H., Klamt, E., Kogel-Knabner, I., Organic matter characteristics and distribution in Ferralsol profiles of a climosequence in southern Brazil. Eur. J. Soil Sci, 57, pp. 644-654, 2006.

[13] Gonzalaz-Pradas, E., Villafranca-Sanchez, M., Fernandez-Perez, M., Socias-Viciana, M., Urena-Amate, M.D., 1998. Sorption and leaching of diuron on natural and peat-amended calcareous soil from Spain. Water Res, 32, pp. 2814-2820, 1998.

[14] Hance, R.J., The adsorption of urea and some of its derivatives by a variety of soils. Weed Res, 5, pp. 98-107, 1965.

[15] Isbell, R.F., The Australian soil classification, CSIRO Publishing, Collingwood, Vic, 2002.

[16] Kang, S., Xing, B., Phenanthrene sorption to sequentially extracted soil humic acids and humins. Environ. Sci. Technol, 39, pp. 134-140, 2005.

[17] Kile, D.E., Wershaw, R.L., Chiou, C.T., Correlation of soil and sediment organic matter polarity to aqueous sorption of nonionic compounds. Environ. Sci. Technol, 33, pp. 2053-2056, 1999.

[18] Liyanage, J.A., Watawala, R.C., Aravinna, A.G.P., Smith, L., Kookana, R.S., Sorption of carbofuran and diuron pesticides in 43 tropical soils of Sri Lanka. J. Agr. Food Chem, 54, pp. 1784-1791, 2006.

[19] Mao, J., Hundal, L.S., Thompson, M.L., Schmidt-Rohr, K., Correlation of poly(methylene)-rich amorphous aliphatic domains in humic substances with sorption of a nonpolar organic contaminant, phenanthrene. Environ. Sci. Technol, 36, pp. 929-936, 2002.

[20] Nkedi-Kizza, P., Rao, P.S.C., Johnson, J.W., Adsorption of diuron and 2,4,5-T on soil particle-size separates. J. Environ. Qual, 12, pp. 195-197, 1983.

[21] Novak, J.M., Moorman, T.B., Cambardella, C.A., Atrazine sorption at the field scale in relation to soils and landscape position. J. Environ. Qual, 26, pp. 1271-1277,1997.

[22] Oliver, D.P., Kookana, R.S., Quintana, B., Sorption of pesticides in tropical and temperate soils from Australia and the Philippines. J. Agr. Food Chem, 53, pp. 6420-6425, 2005.

[23] Salloum, M.J., Dudas, M.J., McGill, W.B., Variation of 1-naphthol sorption with organic matter fractionation: the role of physical conformation. Org. Geochem, 32, pp. 709-719, 2001.

[24] Salloum, M.J., Chefetz, B., Hatcher, P.G., Phenanthrene sorption by aliphatic-rich natural organic matter. Environ. Sci. Technol, 36, pp. 19531958, 2002.

[25] Simpson, M.J., Chefetz, B., Hatcher, P.G., Phenanthrene sorption to structurally modified humic acids. J. Environ. Qual, 32, pp.1750-1758, 2003. 
[26] Skjemstad, J.O., Clarke, P., Taylor, J.A., Oades, J.M., Newman, R.H., 1994. The removal of magnetic materials from surface soils. A solid state 13C CP/MAS n.m.r. study. Aust. J. Soil Res, 32, pp. 1215-1229, 1994.

[27] Teppen, B.J., Laird, D.A., Johnston, C.T., Boyd, S.A., Effects of increasing potassium chloride and calcium chloride ionic strength on pesticide sorption by potassium- and calcium-smectite. Soil Sci. Soc. Am. J, 70, pp. 1889-1895, 2006.

[28] Wauchope, R.D., Yeh, S., Linders, J.B.H.J., Kloskowski, R., Tanaka, K., Rubin, B., Katayama, A., Kordel, W., Gerstl, Z., Lane, M., Unsworth, J.B., Pesticide soil sorption parameters: theory, measurement, uses, limitations and reliability. Pest Manag. Sci, 58, pp. 419-445, 2002.

[29] Xing, B., 1997. The effect of the quality of soil organic matter on sorption of naphthalene. Chemosphere, 35, pp. 633-642, 1997. 